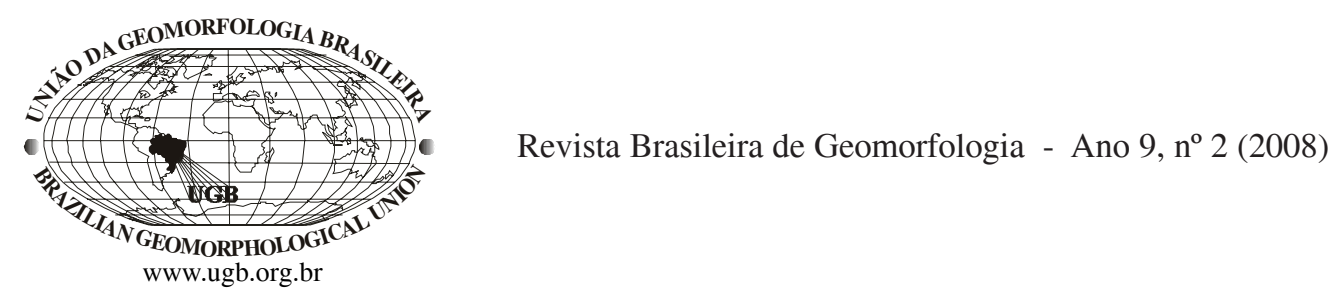

\title{
ASPECTOS GEOMORFOLÓGICOS E CARACTERIZAÇÃO QUÍMICA E ESTRUTURAL DE FORMAÇÕES CONCRECIONÁRIAS DA DEPRESSÃO PERIFÉRICA (RS)
}

Ivaniza de Lourdes Lazzarotto Cabral

Dep. de Geografia/ICHS/UFMT - Av. Fernando Corrêa s/n - Coxipó - 78060-900 Cuiabá - MT. Tel.: (65) 3664-1766 e-mail: ivanizacabral@hotmail.com.A quem correspondência deve ser endereçada.

Rogério Junqueira Prado

Instituto de Física/UFMT - Av. Fernando Corrêa s/n - Coxipó - 78060-900 Cuiabá - MT. Tel.: (65) 3615-8744. Fax.: (65) 3615-8730.

e-mail: rjprado@ufmt.br

\begin{abstract}
Resumo
Neste trabalho foi realizada a análise química de níveis concrecionários em três diferentes situações, localizados no interflúvio entre os rios Ibicuí e Jacuí, na Depressão Periférica do Rio Grande do Sul - município de Cacequi. A presença de níveis concrecionários em blocos, pisolíticos e pisolíticos associados a depósitos de cascalheiras, expressa as duas variações do elemento ferro nas morfologias já mencionadas, indicando transformação e evolução não só da estrutura geológica / geomorfológica, mas das próprias condições pedológicas da região, sob a atual conjuntura climática. Utilizando-se das técnicas de Espectrometria de Raios X por Dispersão em Energia (EDX) e Difração de Raios X (XRD), obteve-se a caracterização química e da estrutura cristalina dos principais componentes pertencentes às três situações morfológicas das concreções. As informações apresentadas permitem verificar que há necessidade de estabelecer algumas revisões em relação aos processos transformadores das superfícies na Depressão Periférica do Rio Grande do Sul, principalmente em relação aos pedogenéticos, pois em uma escala relativamente detalhada tudo indica que na região ocorrem eventos de paleolatossolos e que, sob condições climáticas divergentes às de sua gênese, constituem um dos materiais de origem dos Argissolos na região.
\end{abstract}

Palavras-chave: Níveis concrecionários, Evolução do relevo, Processos pedogenéticos, EDX, XRD.

\begin{abstract}
In this work, concretionary levels found in three different situations, inside the Peripheral Depression of Rio Grande do Sul, were analyzed. These concretionary levels were localized between the Ibicui and Jacui rivers, at the Cacequi municipality - RS (Brazil). The existence of block concretionary levels, ballast and ballast associated to stone lines, express the two variations of the iron element in the mentioned morphologies, indicating transformation and evolution not only of the geological / geomorphological structure, but also of the pedological conditions of the region, under the actual climatic conjuncture. With the Energy Dispersive X-ray Fluorescence Spectrometry (EDX) and X-Ray Diffraction (XRD) techniques, the chemical composition and the main crystalline phases belonging to the three morphological situations found for the concretions were analyzed. The information show that some aspects of the surface transformation processes actuating at the Peripheral Depression of the Rio Grande do Sul need to be revised, mainly the pedogenetic ones. In a detailed scale, all the information indicates the presence of paleoferralsols and that, under climatic conditions that are different of the existent during its genesis process, these soils constitutes one of the origin materials of the clayey soils in the region.
\end{abstract}

Keywords: Concretions levels, relief evolution, pedogenetic processes, EDX, XRD. 


\section{Introdução}

A princípio, o termo laterita foi utilizado para nomear um material macio avermelhado, encontrado nas regiões montanhosas do Malabar na Índia. Esse material, ao ser exposto às condições atmosféricas tornava-se bastante resistente, por isso era explorado e utilizado em construções (PERSONS, 1970; BIGARELLA et al., 1996). A partir dessa referência, o termo laterita foi ampliado para definir os materiais terrosos não endurecidos, ricos em ferro e alumínio. Todavia, vale ressaltar a amplitude de aplicação do termo laterita pelos diferentes profissionais, principalmente aqueles que tratam das questões relacionadas com a origem e formação de solos (CURI et al., 1993; BIGARELLA et al., 1996).

Hidratado ou não, o fato é que o material das formações lateríticas não poderia ser classificado seguindo somente este parâmetro, que colocou em segundo plano questões importantes como, por exemplo, sua composição e a própria morfologia destas formas na natureza.

Neste sentido, a definição de laterita apresentada por Melfi (1994) com base em Schellmann é relevante, pois ao estabelecer que a mesma corresponde a "acumulações superficiais ou subsuperficiais de produtos provenientes do intenso intemperismo de rochas, desenvolvidos sob condições favoráveis a uma maior mobilidade dos elementos alcalinos, alcalinos terrosos, sílica e imobilização de ferro e de alumínio", o autor contempla conteúdos de análise e interpretação da origem destas formas, algo indispensável, uma vez que estas formações podem ser o produto de processos contemporâneos em ambiente tropical atual ou paleolateritas associadas a paleoambientes tropicais.

Outro tópico importante e destacado por Bigarella et al. (1996) é em relação à Geomorfologia. O autor, indiretamente, baseando-se nas idéias de Thomas (1974) e Alexander e Candy (1962), especifica a relação entre os processos que dão origem às formas lateritícas e à evolução do relevo. Essa idéia se evidencia com a citação de Du Preez (1949), que considera laterita uma massa formada essencialmente de óxido de ferro, com ou sem quartzo, e com pequenas quantidades de alumínio e manganês. Esta pode ainda ser vesicular, concrecionária, vermicular, pisolítica ou mais ou menos maciça, desempenhando um papel importante nos aspectos morfológicos do terreno, principalmente na manutenção de antigas superfícies de erosão.

Tal concepção também é apresentada por Penteado (1978), ao contemplar em sua obra dois subitens denominados de "O papel das couraças na morfologia" e "A importância das couraças na morfogênese".

Mesmo não entrando no mérito das diferenças entre as várias nomenclaturas utilizadas para definir formas ferruginosas ou não, de aspecto endurecido, resultantes dos processos de intemperismo químico, Penteado (1978) evidencia a importância das carapaças ferruginosas no desenvolvimento do relevo, pois elas conservam antigas superfícies de erosão; desenvolvem superfícies aplainadas, seguidas de vertentes côncavas; e balizam níveis de Paleossolos, tornando-se um ponto de referência para o estudo do desenvolvimento do relevo e da própria pedologia.

Em termos de caracterização, Kellogg (1949) apud Bigarella et al. (1996) estabelece como laterita somente os materiais ferruginosos que endurecem ao entrar em contato com o ar, assim como as formas fósseis (paleolateritas). Já o "Sistema Americano de Classificação de Solos" - U.S. Soil Survey (1960) reconhece quatro formas principais: a) argilas mosqueadas que se transformaram irreversivelmente em material endurecido por exposição ao ar; b) crostas ou níveis endurecidos celulares ou mosqueados; c) concreções ou nódulos misturados com material não endurecido; e d) massas consolidadas de concreções ou nódulos.

Outros aspectos relacionados aos níveis e/ou lentes ferruginosas se referem à variação de endurecimento e à cor do material. O primeiro está relacionado a determinados fatores como: a) composição e grau de cristalização dos minerais; b) o arranjo estrutural dos diferentes constituintes e c) cronologia de formação. $\mathrm{O}$ segundo refere-se às diferentes tonalidades dos compostos, que podem variar do rosa, ocre, vermelho e castanho (BIGARELLA et al., 1996).

Estes aspectos estão vinculados à própria dinâmica de formação dos compostos ferruginosos quando expostos às condições ambientais que propiciam sua gênese, determinando variação no grau de transformação química dos compostos envolvidos nas reações químicas de todo o processo.

Outro fato diferenciado nos meios superficiais ferruginosos é o seu aspecto químico/mineralógico. Em geral, as formações lateríticas apresentam elevados teores de sesquióxidos de ferro ou alumínio ${ }^{1}$ em conjunto com outros componentes como, por exemplo, a sílica residual ou de neoformação (BIGARELLA et al., 1996; TARDY, 1993).

Estes autores destacam ainda que nos meios superficiais ferruginosos a presença do ferro ocorre, principalmente, sob a forma de Goethita e de Hematita, podendo ainda ocorrer outras formas de ferro, como o magnético, enquanto nas lateritas aluminosas predominam os óxidos hidratados de alumínio (Gibsita).

A mobilidade dos principais elementos que compõem as concreções está relacionada à dinâmica hídrica de subsuperfície, determinada pelas condições climáticas, geológicas e geomorfológicas das mesmas.

Sob a atuação de climas regidos por temperaturas relativamente elevadas e períodos destacados de déficit e exce-

\footnotetext{
${ }^{1}$ Principais elementos responsáveis pelo endurecimento dos horizontes lateríticos.
} 
dente pluviométrico, as superfícies aplainadas dos continentes são submetidas à ação do intemperismo químico que constrói e reconstrói suas formas, juntamente com as estruturas das rochas que as compõem. Ao contrário dos processos mecânicos de transformação do relevo, a formação e o equilíbrio das formas concrecionárias e/ou lateríticas é algo que se desenvolve lentamente, envolvendo longos períodos de tempo. Com base nas informações estabelecidas por Nahon (1986) e Nahon \& Tardy (1992), e destacadas por Porto (1996), um perfil laterítico completo leva em torno de 1 a 6 milhões de anos para se formar, a uma velocidade de 20 a 40 mm a cada 1000 anos.

As formas paleolateríticas fazem conjunto com os paleossolos, pois os processos de sua formação se interagem aos pedogenéticos (MEYER, 1987). É neste contexto que a própria definição e classificação pedológica para algumas áreas da Depressão Periférica no Rio Grande do Sul, principalmente a área que abrange o interflúvio Ibicuí-Jacuí, necessita de uma revisão detalhada, uma vez que os fatos aqui tratados são freqüentes e estão relacionados a eventos paleoambientais, que possibilitaram não só a formação de níveis concrecionários, mas também o desenvolvimento de perfis de Latossolos e, atualmente, consistem em ocorrências de Latossolos associados aos Argissolos e/ou paleolatossolos associados a Argissolos, sob contexto de transformação dos componentes sedimentares.

Com o propósito de divulgar a existência de tais eventos foi realizada a caracterização geomorfológica, química e da estrutura cristalina de algumas amostras de materiais concrecionários e não-concrecionários (substrato e cobertura) presentes em diferentes situações morfológicas de níveis concrecionários em meio sedimentar na região, sob condições ambientais desfavoráveis à laterização.

\section{Área de estudo}

A área onde ocorrem os níveis concrecionários corresponde a superfícies colinosas, drenadas pelos afluentes da margem esquerda do médio rio Ibicuí. A localidade da vila de Umbu, a voçoroca situada na área da fazenda Umaitá e o corte da estrada junto à comunidade do Macaco Branco, onde foram estabelecidos os pontos de coleta das amostras de concreções e dos materiais sobre e subjacentes, fazem parte do conjunto interfluvial até então mantido por estes níveis que são os mais resistentes de todo o conjunto sedimentar. Mapa 1.

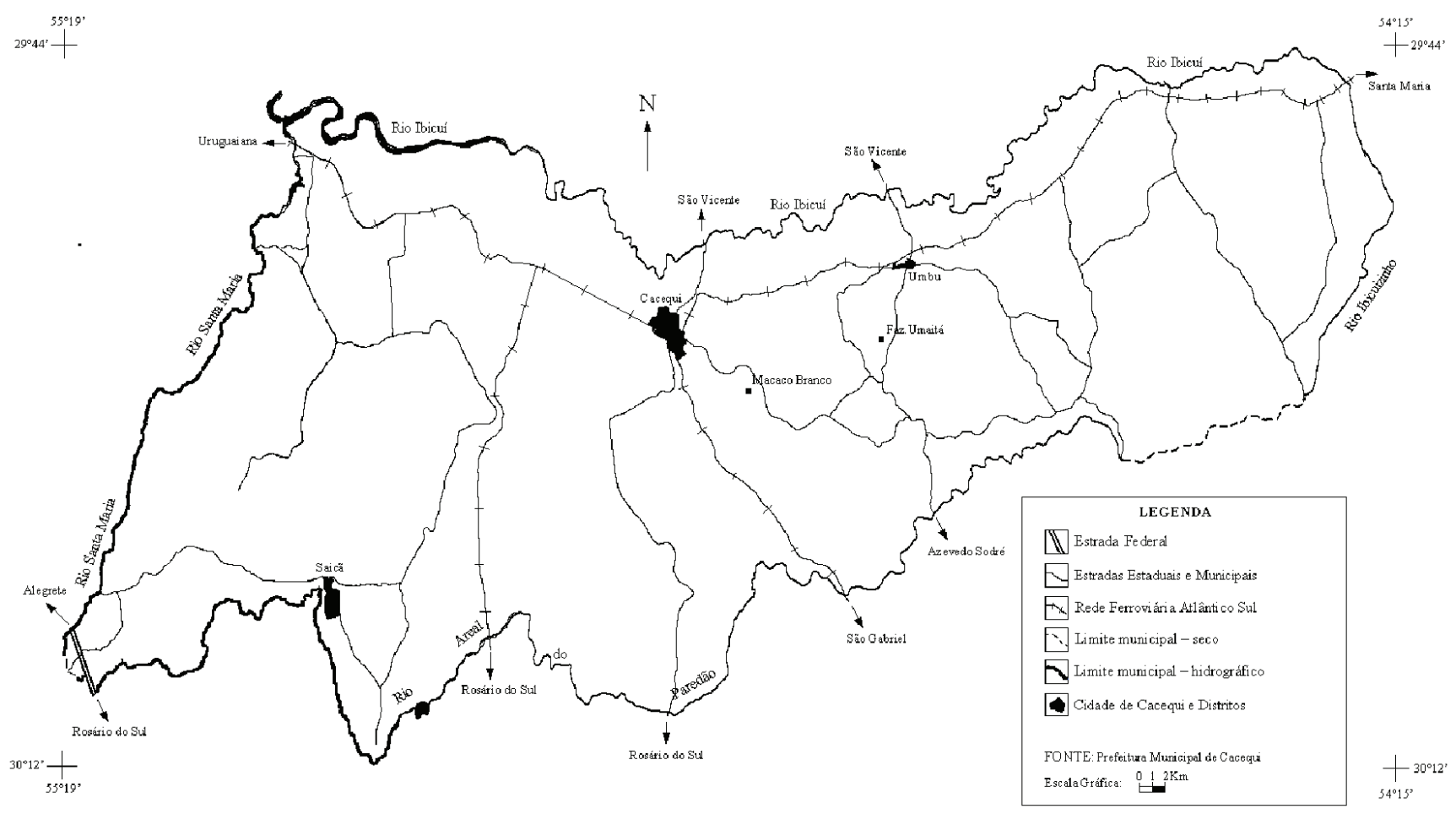

Mapa 1 - Localização dos pontos de coleta das amostras no município de Cacequi - RS 
O domínio morfoestrutural das bacias e coberturas sedimentares, na Depressão Periférica do Rio Grande do Sul, abrange as composições litológicas da Bacia Sedimentar do Paraná originadas durante a fase de sedimentação Paleozóica/ Mesozóica, nas efusivas Jurocretácicas e nas coberturas terciárias. Projeto RADAMBRASIL (BRASIL, 1986; SCHERER et al., 2002).

Estabelecidas nestes meios, as formas de relevo em colinas amplas caracterizam-se pela presença de elevações alongadas, com declives/aclives de baixos valores e pequenas altitudes relativas, denotando uma condição de relevo semi-plano na região, ou seja, as típicas "coxilhas" pampeanas do estado.

Em termos de ambiente climático, o Rio Grande do Sul faz parte da faixa tropical a temperada, onde as características do tipo climático mesotérmico úmido, sem estação seca, apresenta-se sob influência dos centros de ação atmosférica do Anticiclone Polar, Anticiclone do Pacífico e Anticiclone do Atlântico (VIEIRA, 1984; NIMER, 1989).

Especificamente, conforme a classificação de Köppen, a área onde ocorrem os fatos aqui tratados faz parte da zona de clima subtropical úmido do tipo $\mathrm{Cfa}$, onde as precipitações médias anuais variam de 1300 a $1500 \mathrm{~mm}$ e as temperaturas do mês mais frio oscilam, em média, entre $3{ }^{\circ} \mathrm{C}$ e $18^{\circ} \mathrm{C}$ e as do mês mais quente são superiores a $22^{\circ} \mathrm{C}$.

Entretanto, cabe destacar que a distribuição dos índices definidores do tipo climático para a região apresentam variações no decorrer das sucessões rotineiras de seus elementos. $\mathrm{O}$ comportamento pluviométrico mais torrencial durante o verão e menos no inverno, a irregularidade das precipitações ao longo do ano e a variação significativa dos totais pluviométricos mensais e anuais expressam uma tendência à ocorrência de anos padrão normais ou chuvosos na região central do Rio Grande do Sul (BARROS SARTORI, 1993).

Esse fato, quando associado a fatores climáticos relevantes para uma maior ou menor permanência de umidade nos sistemas superficiais, confere uma variabilidade nos padrões hídricos que atuam nos sistemas pedológicos entre as estações do ano inverno e verão, particularizando, em escala de maior detalhe, situações pedogenéticas cíclicas, entre inverno e verão, no meio em questão.

Em termos fitogeográficos, a área pertence ao ecossistema de estepe estacional com vegetação predominantemente rasteira, intercalada ou não por matas de galeria ou capões, correspondendo ao conjunto florístico estacional decidual (LEITE, 2002).

O primeiro conjunto vegetal faz parte dos campos de pradarias, caracterizados por uma vegetação rasteira ou não, conferindo-lhes subdivisões que expõem o tipo florístico desta unidade vegetal em cada área, ou seja: campos sujos, campos finos e campos limpos, compostos por espécies de poáceas como, por exemplo, a grama Aristida, Axonopus, Cyperacea e Leguminosae, entre outras (QUADROS \& PILLAR, 2002).

Conforme Bolzan \& Marchiori (2002), estes campos são testemunhos das variações climáticas que ocorreram na América do Sul no decorrer dos últimos acontecimentos glaciais e interglaciais. $\mathrm{Na}$ área estudada, estes complexos florísticos ocorrem em solos Argissolos e Latossolos, bem drenados.

O segundo conjunto florístico, as matas de galeria e os “capões" são típicos dos locais mais úmidos, e estão associados aos locais de solos mal drenados presentes ao longo dos cursos d'água, ou junto às partes mais rebaixadas do terreno, sob influência constante do nível freático. De acordo com Leite (2002), esse aspecto florístico se manifesta em ambiente climático com precipitação anual superior a $1250 \mathrm{~mm}$, sem um nítido e sistemático período seco, porém com destaques, em termos de temperaturas, entre inverno e verão, conferindo um balaço hídrico negativo de até $100 \mathrm{~mm}$ na região. Esse déficit hídrico é um fato que ocorre em anos normais ${ }^{2}$ durante o verão.

\section{Procedimento Metodológico}

Duas linhas de atividades fizeram parte do procedimento geral da obtenção e análise dos materiais concrecionários, sob perspectiva macro e microescalar, ou seja, o reconhecimento e entendimento morfológico destas estruturas no relevo regional e a caracterização química dos principais componentes das estruturas concrecionárias e de seus respectivos materiais de recobrimento e subjacentes.

\section{Levantamento de campo}

O reconhecimento e o entendimento morfológico das estruturas concrecionárias nas topografias colinosas do relevo regional levou em consideração a distribuição espacial destas formas em relação ao nível hipsométrico, ao tamanho e forma dos campos de infiltração - dissecação, declividade geral, aspectos dos processos morfopedológicos em vigor, cobertura vegetal e tipo de uso e ocupação da terra.

A presente análise teve suporte e deu continuidade a uma parte do trabalho desenvolvido por Cabral (2004). Com várias informações a respeito do desenvolvimento do relevo, das características pedológicas e dos fatores morfodinâmicos atuantes, fez-se a coleta de amostras dos

\footnotetext{
${ }^{2}$ Aqui, cabe destacar que anos normais de precipitação na região são aqueles que apresentam índice em torno de 1300 a 1800 mm (Barros Sartori, 1993).
} 
seguintes materiais: cobertura superficial, pois todos os níveis concrecionários apresentam-se recobertos por algum tipo de material; concreções em conjunto com níveis de depósitos fluviais; concreções em blocos - material concrecionário cimentado por material férrico alterado; material concrecionário puro e material sedimentar subjacente.

\section{Ensaios Químicos e Estruturais}

As análises químicas por Espectrometria de Raios X por Dispersão em Energia - EDX (Jenkins, 1999) e da estrutura cristalina por Difração de Raios X - XRD (GUINIER, 1994), foram realizadas no Laboratório Multiusuário de Técnicas Analíticas (LAMUTA) do Instituto de Ciências Exatas e da Terra (ICET) da Universidade Federal de Mato-Grosso (UFMT).

As amostras analisadas neste trabalho foram pulverizadas e homogeneizadas num moinho com panela (e cilindros) de carbeto de tungstênio (Marca AMEF). O tempo de processo foi de 180 segundos. Para as amostras de 1 a 5 , foram pulverizadas concreções inteiras, de aproximadamente 2 a $3 \mathrm{~cm}$ de diâmetro.

Para a realização das análises químicas, foram preparadas pérolas vítreas de tetraborato de lítio anidro num equipamento de fusão Katanax K1. Na preparação de cada pérola foram utilizadas $0.6 \mathrm{~g}$ de material pulverizado, adicionando-se uma razão de 10:1 de tetraborato de lítio anidro por grama de material.

As pérolas vítreas foram utilizadas para a determinação da concentração média dos elementos maiores e menores presentes nas amostras de 1 a 5, e/ou nas diferentes camadas da amostra 6. Para isso utilizou-se um equipamento Shimadzu EDX-700HS, capaz de realizar análises semiquantitativas por meio de padrões internos através da rotina Quali-Quant FP. A precisão das quantificações foi verificada por meio da análise de amostras conhecidas (padrões) de composição próxima à das amostras estudadas. Os erros observados para as fases maiores presentes nos padrões foram menores que $1 \%$, atestando a precisão dos resultados. Para cada espectro utilizou-se um tempo de contagem de 300 segundos.

Todos os espectros foram adquiridos em vácuo, de maneira a melhorar a precisão das medidas para os elementos mais leves, cujas radiações características são fortemente absorvidas pela matéria (inclusive pelo próprio ar).
Os perfis de difração de raios $\mathrm{X}$ foram obtidos com o auxílio de um Difratômetro Shimadzu XRD-6000, equipado com tubo de Cobre $(\mathrm{Cu})$ fixo e monocromador, na geometria de Bragg-Brentanno $(\theta-2 \theta)$. Os perfis foram adquiridos entre 5,0 e 120,0 graus, com passos de 0,004 graus, tempo de aquisição por passo de 3 segundos, fendas de divergência e espalhamento de 1 grau e fenda de recepção de 0,30. Para isso, o material pulverizado foi devidamente montado num porta-amostra de preenchimento frontal, conforme o procedimento descrito por Buhrke et al. (1998). A determinação do tamanho médio de cristalito das fases Hematita e Goethita, presentes nas diversas amostras foi feita utilizando a fórmula de Scherrer (WARREN, 1990; GUINIER, 1994; HAMMOND, 2001).

\section{Resultados}

\section{As concreções e a dinâmica morfológica regional}

$\mathrm{O}$ conhecimento das diferentes situações nas quais se apresentam os níveis concrecionários na região é importante, pois estas particularidades apresentam informações chave para o seu entendimento genético, e também sobre a evolução da própria paisagem na qual estão inseridas.

Sendo assim, várias informações obtidas em campo e/ ou em mapas temáticos da região - Mapa Clinográfico e Topográfico, escala 1:50000 (CABRAL, 2004) - permitiram estabelecer uma síntese descritiva do local de cada amostra analisada em laboratório.Tabela I.

Como mencionado anteriormente, também foram feitas coletas de amostras do material situado sobre e subjacentes aos níveis de concreções das três situações identificadas. A tabela II apresenta a descrição destes materiais in loco.

As informações sintetizadas nas Tabelas I e II, juntamente com estudo prévio da área, forneceram subsídios para o entendimento do papel desempenhado pelas concreções na evolução do relevo. Essa análise permitiu destacar alguns fatos envolvendo as concreções na paisagem, ou seja: a) os níveis concrecionários nas variações blocos e pisolíticos constituem topos de paleosuperfícies que, sujeitas a um ambiente climático diferente do atual, desenvolveram processos pedogenéticos de laterização em meio sedimentar (AB' SABER, 1995); b) as concreções pisolíticas com depósitos fluviais correspondem ao retrabalhamento dos materiais citados anteriormente, numa fase de clima mais úmido, sob a ação da rede de drenagem sujeita a movimentos neotectônicos ${ }^{3}$ que rebaixaram e "continuam" a rebaixar o

\footnotetext{
${ }^{3}$ A inferência sobre movimentos neotectônicos na região partiu da observação de fatos relacionados a intensidade dos processos de voçorocamentos cíclicos em cabeceiras da drenagem de tributários do rio Ibicuí, ou seja, presença de voçorocas ?estacionadas? - com cobertura vegetal? voçorocas em amplo desenvolvimento - sem cobertura vegetal e voçorocas reativadas - vegetadas com processos de entalhamento erosivo em seus leitos, além dos vários registros de rios entalhando seus próprios depósitos (Cabral, 2004? Cabral \& Ross, 2004). Cabe destacar que a área em questão faz parte do Eixo São Grabriel/Santa Maria (Leinz, 1949? Ab’ Saber, 1964? Sherer, Faccini \& Lavina, 2002).
} 
nível de base regional; e c) atualmente estas formas desempenham papel fundamental na evolução topográfica e possibilitam, juntamente com a questão estrutural, o surgimento de interflúvios com topos rebaixados sujeitos à ação de processos hidromórficos. A interpretação da evolução do

interflúvio com seus respectivos registros é apresentada no esquema da figura 1 .

Tabela I - Detalhes morfológicos das amostras concrecionárias.

\begin{tabular}{|c|c|c|}
\hline Amostra & $\begin{array}{c}\text { Alt.(m) } \\
\text { Decl.(\%) }\end{array}$ & Descrição \\
\hline 1 & $4-6$ & $\begin{array}{l}\text { - Composição pisolítica com depósito fluvial subjacente composto por fragmentos de troncos silicificados, } \\
\text { blocos arredondados de quartzo. } \\
\text { - Nível concrecionário situado a um metro de profundidade, recoberto por uma camada sedimentar } \\
\text { composta por areia fina e argila de cor vermelho ocre, pouco estruturada, muito semelhante aos espessos } \\
\text { horizontes de Latossolos. Amostra A - Tabela II. } \\
\text { - O nível pisolítico, junto com o depósito fluvial tem } 70,0 \mathrm{~cm} \text { de espessura. } \\
\text { - O conjunto concre cionário com o depósito fluvial situa-se discordantemente sobre um arenito médio a fino } \\
\text { bem estruturado de cor rosa. } \\
\text { - Local de coleta da amostra: voçoroca de grande porte situada em cabeceiras de drenagem. }\end{array}$ \\
\hline 2 & $4-6$ & $\begin{array}{l}\text { - Concreções pisolíticas e depósito fluvial recobertos por cerca de } 2,5 \text { metros de sedimentos compostos por } \\
\text { areia fina e argila, pouco estruturado de cor vermelho ferruginoso. } \\
\text { - O nível de concreções pisolíticas está situado sobre a linha de cascalheira e esta sobre o arenito rosa } \\
\text { estruturado. Amostra B - Tabela II. } \\
\text { - O conjunto, linha de concreções mais a cascalheira, perfazem } 60 \mathrm{~cm} \text { de espessura. } \\
\text { - Local de coleta da amostra: voçoroca de grande porte situada em cabeceira de drenagem. }\end{array}$ \\
\hline 3 & $1-4$ & $\begin{array}{l}\text { - Nível concrecionário pisolítico sem a presença de cascalheiras. } \\
\text { - Situado a } 1,0 \mathrm{~m} \text { de profundidade o nível concrecionário encontra-se recoberto por material superficial } \\
\text { hidromorfisado de granulometria muito fina a fina (areia). Apresenta cor cinza escura. Presença de } \\
\text { matéria orgânica junto à superfície. Amostra C - Tabela II. } \\
\text { - Nível de concreção pisolítica situado junto a o topo de uma colina ampla, com ocorrência de rebaixamento } \\
\text { em topos de colina, local de hidromorfia. }\end{array}$ \\
\hline 4 & $4-6$ & $\begin{array}{l}\text { - Nível concrecionário em bloco. Apre senta material cimentante com certo grau de alteração. } \\
\text { - Nível concrecionário mais inteiro, com formas pisolíticas maiores e mais resistentes. Apresenta 1,5 metro } \\
\text { de espessura e está recoberto por } 50 \mathrm{~cm} \text { de material sedimentar vermelho ocre. Amostra E - Tabela II. } \\
\text { - No topo do nível concrecionário ocorre, em conjunto com as formas mais maciça, formas concrecionárias } \\
\text { pisolíticas, constituindo uma zona de contato entre os sedimentos superficiais e o bloco concrecionário. } \\
\text { - Material concrecionário de sustentação das superfícies em geral. } \\
\text { - Local de ocorrência: junto ao topo de uma colina ampla. }\end{array}$ \\
\hline 5 & 120 & $\begin{array}{l}\text { - Peque no nível pisolítico situado na parte superior do nível concrecionário em bloco. } \\
\text { - Nível concrecionário mais inteiro, têm formas pisolíticas maiores e mais resistentes. Apresenta 1,5 metro } \\
\text { de espessura e está recoberto por } 50 \mathrm{~cm} \text { de material sedimentar vermelho ocre. Amostra E - Tabela II. }\end{array}$ \\
\hline 6 & $4-6$ & $\begin{array}{l}\text { - Nível concrecionário em blocos, constituído por formas bem maiores que os nódulos pisolíticos, } \\
\text { responsáveis por uma estrutura com a seguinte organização: a) material ferruginoso cimentante de cor } \\
\text { amarelada - material ferruginoso na forma Goethita; b) carapaça ferruginosa de cor escura, muito } \\
\text { resistente, com elevada quantidade de sílica e, c) parte interna da carapaça, material menos resistente de } \\
\text { cor vermelho forte, composto por ferro na forma Hematita. } \\
\text { - Situa-se na parte superior de uma colina ampla. Apresenta-se recoberta por uma camada não muito espessa } \\
\text { de sedimentos já caracterizados na segunda descrição da amostra } 4 \text { e } 5 \text {. Amostra E - Tabela II. }\end{array}$ \\
\hline
\end{tabular}

Fonte: Cabral (2004) e trabalho de Campo (maio de 2005). Amostras 1 e 2 - Faz. Umaitá;. Amostra 3-Macaco Branco; Amostras 4, 5 e 6 - Umbu.

O diagrama esquemático da figura 1 permite a compreensão do contexto geral das unidades concrecionárias na atual conjuntura morfológica em vigor. Em termos de inclusão morfológica dos eventos concrecionários, o referido esquema apresenta de forma sucinta a dinâmica evolutiva da paisagem geral da região, tendo os seus primórdios associados aos eventos da própria evolução da Depressão Periférica, acondicionada pelos seus dois principais eixos de drena- gem. No contexto evolutivo da Depressão Periférica, os eventos tectônicos associados aos processos morfopedológicos permitiram o surgimento dos produtos que constituem os substratos de onde se originaram os níveis concrecionários na região.

$\mathrm{Na}$ busca de melhor entender a diversidade dos materiais presentes nas superfícies colinosas, o esquema apresentado na figura 1 supõe que as coberturas 
sedimentares nas quais apresentam-se inseridas as três variações morfológicas de concreções de óxido de ferro podem ser derivadas de unidades sedimentares do Grupo Rosário do Sul (Triássico), de remanescentes da Formação Mata (Triássico Superior) e/ou do retrabalhamento de ambas.
A figura 1 também apresenta a interação dos eventos concrecionários com as diferentes situações morfológicas e estruturais presentes na área, ou seja, voçorocamentos em cabeceiras de drenagem e formas rebaixadas em topos de colinas perfazendo, na atualidade, o conjunto de fatos responsáveis pela transformação das superfícies nesta parte da Depressão Periférica (CABRAL \& ROSS, 2004).

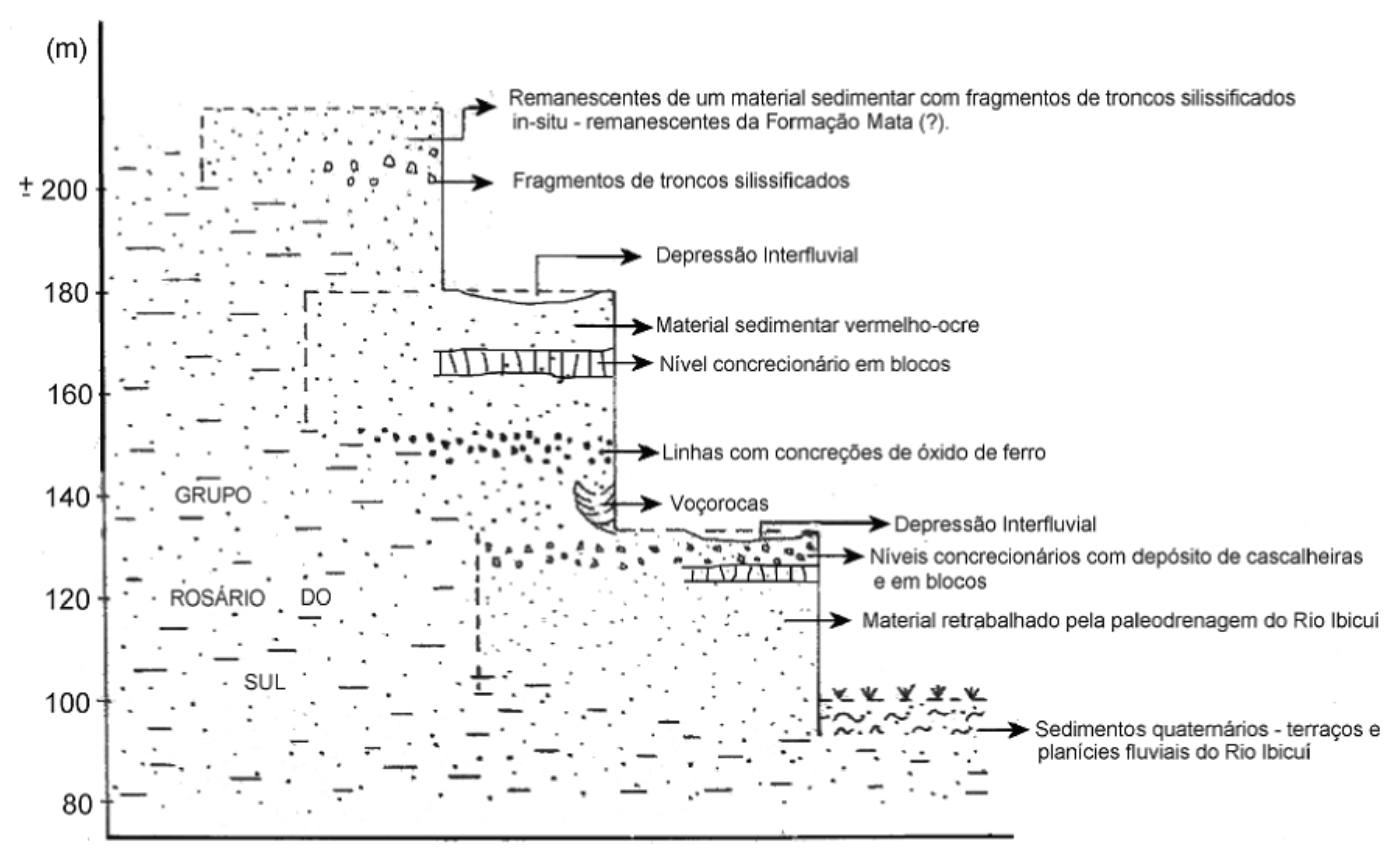

Figura 1 - Distribuição topográfica das coberturas sedimentares e dos tipos concrecionários

Fonte: Modificado de Cabral (2004).

Tabela II - Detalhes gerais das amostras do material sobre e subjacentes aos níveis concrecionários.

\begin{tabular}{c|c|c|l}
\hline Amostra & $\begin{array}{c}\text { Alt / Dec } \\
(\mathrm{m})(\mathbf{\%})\end{array}$ & Localização & \multicolumn{1}{|c}{ Descrição } \\
\hline $\mathrm{A}$ & $\begin{array}{c}170 \\
4-6\end{array}$ & $\begin{array}{c}\text { Sobre o nível } \\
\text { concrecionário }\end{array}$ & $\begin{array}{l}\text { Sedimento pouco estruturado, vermelho ocre com granulometria } \\
\text { média a fina - silte/argila-e matriz ferruginosa. bastante friável. }\end{array}$ \\
\hline $\mathrm{B}$ & $\begin{array}{c}170 \\
4-6\end{array}$ & $\begin{array}{c}\text { Subjacente ao nível } \\
\text { concrecionário }\end{array}$ & $\begin{array}{l}\text { Arenito bem estruturado, rosa, de granulometria média a fina } \\
\text { relativamente selecionado, bastante friável, face fluvial do Grupo } \\
\text { Rosário do sul - Triássico. Perfil relativamente espesso, cerca de 6 } \\
\text { metros. }\end{array}$ \\
\hline $\mathrm{C}$ & 120 & $\begin{array}{c}\text { Sobre o nível } \\
\text { concrecionário }\end{array}$ & $\begin{array}{l}\text { Material sedimentar bastante intemperizado, arenoso, de cor cinza } \\
\text { escuro, com presença de matéria orgânica. Perfil com 70 cm de } \\
\text { espessura. }\end{array}$ \\
\hline $\mathrm{D}$ & $\begin{array}{c}120 \\
4-6\end{array}$ & $\begin{array}{c}\text { Subjacente ao nível } \\
\text { concrecionário }\end{array}$ & Material ferroso bastante intemperizado de cor amarelada. \\
\hline $\mathrm{E}$ & 160 & $\begin{array}{c}\text { Sobre o nível } \\
\text { concrecionário }\end{array}$ & Idem primeira descrição. \\
\hline \hline & 160 & $\begin{array}{c}\text { Subjacente ao nível } \\
\text { concrecionário }\end{array}$ & $\begin{array}{l}\text { Material semelhante ao que está sobre o nível concrecionário, porém } \\
\text { mais alterado. Cor: vermelho amarelo. }\end{array}$ \\
\hline \hline
\end{tabular}

Fonte: Cabral (2004) e trabalho de Campo (maio de 2005). Amostras A e B - Faz. Umaita. Amostras C e D - Macaco Branco. Amostras E e F-Umbu. 
Características químicas e estruturais dos materiais concrecionários e sedimentares sobre e subjacentes às concreções

Durante a coleta dos materiais em campo, verificou-se que os materiais concrecionários apresentavam uma estrutura de camadas. Nas amostras 4, 5 e 6 (material concrecionário em bloco), a camada mais externa é composta por material de cor amarela, correspondendo a parcelas do conteúdo de material cimentante de unidades nodulares presentes no conjunto desta variação concrecionária. Já a camada intermediária era escura e altamente resistente, enquanto que a camada interna, mais clara que a camada intermediária, apresentava tons variando entre vermelho e amarelo, e não era muito resistente. As amostras 1, 2 e 3, por serem pisolíticas, não apresentavam a camada de material cimentante mais externa.

Com o objetivo de melhor caracterizar essas camadas, fez-se a separação e pulverização de material suficiente de cada camada da amostra 6, permitindo sua análise química e da estrutura cristalina, seguindo as mesmas condições utilizadas para as demais amostras. A camada mais externa foi denominada 6x, a intermediária 6y e a mais interna 6z, conforme esquematizado na figura 2.

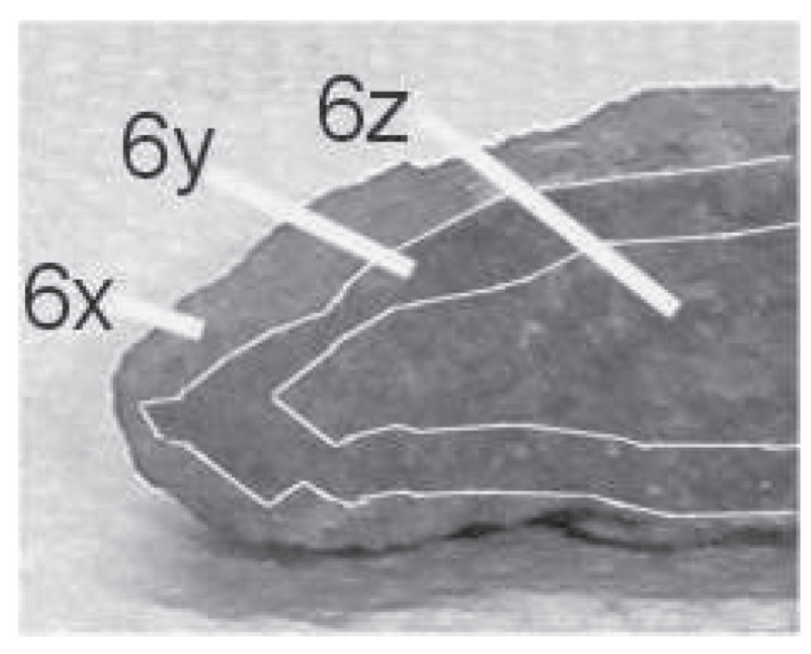

Figura 2 - Amostra 6 e suas respectivas camadas. Foram introduzidas linhas brancas nesta figura para uma melhor visualização das mesmas.

A tabela III apresenta a composição química média das variações concrecionárias pisolíticas e em blocos, como descritas na tabela I. Conforme os dados apresentados nesta ta- bela, os tipos analisados tratam-se de concreções ferruginosas (e não aluminosas), inferência essa obtida a partir da proposta de Schellmann (1982) apud Melfi (1994).

Tabela III - Composição química das variações concrecionárias pisolíticas e em blocos.

\begin{tabular}{c|c|c|c|c|c|c|c|c|c}
\hline \multirow{2}{*}{ Amostras } & \multicolumn{10}{|c}{ Concentração média dos principais componentes (\%) } \\
\cline { 2 - 11 } & $\mathrm{SiO}_{2}$ & $\mathrm{Fe}_{2} \mathrm{O}_{3}$ & $\mathrm{Al}_{2} \mathrm{O}_{3}$ & $\mathrm{TiO}_{2}$ & $\mathrm{ZrO}_{2}$ & $\mathrm{CuO}$ & $\mathrm{Cr}_{2} \mathrm{O}_{3}$ & $\mathrm{As}_{2} \mathrm{O}_{3}$ & $\mathrm{ZnO}$ \\
\hline 1 & 50,4 & 42,2 & 7,1 & 0,27 & 0,028 & - & - & - & - \\
\hline 2 & 58,9 & 33,6 & 7,2 & - & 0,033 & 0,028 & 0,15 & 0,023 & - \\
\hline 3 & 53,5 & 33,2 & 12,4 & 0,76 & 0,052 & 0,026 & 0,064 & 0,041 & - \\
\hline 4 & 58,0 & 29,9 & 11,3 & 0,76 & 0,017 & 0,034 & - & - & - \\
\hline 5 & 58,6 & 28,6 & 11,9 & 0,76 & 0,015 & 0,032 & 0,11 & - & - \\
\hline $6 \mathrm{x}$ & 72,4 & 15,1 & 11,5 & 0,87 & 0,034 & 0,022 & - & - & 0,030 \\
\hline $6 \mathrm{y}$ & 47,1 & 42,4 & 9,6 & 0,82 & 0,025 & - & - & - & - \\
\hline $6 \mathrm{z}$ & 58,0 & 31,9 & 9,4 & 0,55 & 0,036 & - & - & - & 0,10 \\
\hline
\end{tabular}

OBS: Amostras 1 e 2 - Faz Umaitá. Amostra 3 - Macaco Branco. Amostras 4, 5 e 6 - Umbu. 6 x representa a parte cimentante do material concrecionário em bloco; 6y a camada superficial das concreções propriamente ditas; e $6 z$ o núcleo da concreção. 
Deve ser mencionado que a técnica de EDX não permite identificar se átomos de um determinado elemento químico estão presentes em mais de uma fase estrutural do material. Ela nos fornece, somente, a quantidade total de um determinado elemento químico presente na amostra analisa$\mathrm{da}$, independentemente da(s) fase(s) estrutural(is) na(s) qual(is) ele se encontre neste material. Este é, por exemplo, o caso do ferro $(\mathrm{Fe})$, que se encontra nas fases Goethita $(\mathrm{FeO} . \mathrm{OH})$ e Hematita $\left(\mathrm{Fe}_{2} \mathrm{O}_{3}\right)$. Portanto, a tabela III apresenta informações apenas sobre a quantidade total de ferro presente em cada amostra analisada.

Sendo assim, em relação à variabilidade dos principais elementos químicos presentes, as amostras analisadas se mostraram homogêneas, pois a ocorrência de outros elementos é pequena e pode ser relacionada à contaminação. Comparando-se os resultados obtidos para as amostras das três variações morfológicas do material concrecionário, observa-se que as unidades amostrais pertencentes às formas pisolíticas (amostras 1, 2 e 3) tiveram valores com alguma diferenciação em seus principais componentes. As formas pisolíticas associadas a depósitos fluviais, amostras 1 e 2, apresentaram uma composição química diferenciada (menor) em relação a fase $\mathrm{Al}_{2} \mathrm{O}_{3}$, se comparada às demais amostras. Esse fato pode ser relacionado ao evento de remanejamento das formas concrecionárias na região por parte da paleodrenagem do rio Ibicuí, que promoveu maior saída do $\mathrm{Al}_{2} \mathrm{O}_{3}$ do sistema concrecionário. Isso permite estabelecer parâmetros para a individualização não só das unidades concrecionárias, mas também do material sedimentar sobrejacente às mesmas, pois ambas constituem o conjunto de material remanejado que, em vários casos, recobrem as superfícies colinosas na região.

A amostra 3, formas pisolíticas sem depósitos de cascalheiras, constitui um caso à parte se comparado às demais, pois foi a amostra que manifestou maior valor no elemento $\mathrm{Al}_{2} \mathrm{O}_{3}$. Esse fato pode ser relacionado à própria condição morfológica de onde foi retirada a amostra, ou seja, em topo de colina ampla o nível concrecionário se degrada formando unidades de Argissolos nos topos desta categoria de dimensão colinosa. Con- sistem em produtos resultantes de processos pedogenéticos promovedores de formas rebaixadas em topos de colinas extensas da região. Essa variedade concrecionária pode ser referência para o entendimento e separação entre as coberturas sedimentares in situ e as de remanejamento.

As amostras 4 e 5, níveis concrecionários em blocos, mantêm quantidades relativamente importantes dos principais elementos analisados, indicando uma melhor preservação em relação as amostras 1 e 2. Isso possibilita estabelecer a hipótese de que estes materiais constituem superfícies remanescentes de ambientes favoráveis ao concrecionamento na região e, sob a atual condição, encontram-se em processo de degradação. Estas formações, assim como as demais, constituem um dos requisitos suporte para entender e separar as unidades sedimentares depositadas (remanejamento de materiais) e transformadas (in situ), que recobrem as colinas desta e de outras partes da Depressão Periférica.

Assim, levando em consideração a individualização dos materiais que compõem as referidas amostras (principalmente o $\mathrm{Al}_{2} \mathrm{O}_{3}$, presente em maior quantidade), percebe-se que o material concrecionário em bloco constitui (assim como o material da amostra 3) o material concrecionário original no qual as variações morfológicas são os reflexos da dinâmica de alteração sofrida por estes materiais.

O detalhamento da amostra concrecionária em bloco, amostra 6 e figura 2, permitiu observar que a degradação destas formas ocorre de fora para dentro e promove uma silicificação por metassomatismo destes materiais, ou seja, de concreções ferruginosas passa-se a ter algo mais associado à sílica.

Junto à caracterização do material concrecionário, também foram analisados os materiais situados imediatamente acima e abaixo dos referidos níveis. Em termos gerais, conforme os dados obtidos e apresentados na tabela IV, observase que os materiais entre os quais os níveis concrecionários encontram-se embutidos são ricos em sílica, mas apresentam $\mathrm{Al}_{2} \mathrm{O}_{3}, \mathrm{Fe}_{2} \mathrm{O}_{3}$ e outros materiais com menor expressividade.

Tabela IV - Composição química das variações sedimentares sobre e subjacentes aos níveis concrecionários.

\begin{tabular}{c|c|c|c|c|c|c}
\hline \multirow{2}{*}{$\begin{array}{c}\text { PRINCIPAIS } \\
\text { COMPONENTES }\end{array}$} & \multicolumn{7}{c}{ AMOSTRAS } \\
\cline { 2 - 7 } & $\begin{array}{c}\mathrm{A} \\
\text { sobre }\end{array}$ & $\begin{array}{c}\mathrm{B} \\
\text { sub }\end{array}$ & $\begin{array}{c}\mathrm{C} \\
\text { sobre }\end{array}$ & $\begin{array}{c}\mathrm{D} \\
\text { sub }\end{array}$ & $\begin{array}{c}\mathrm{E} \\
\text { sobre }\end{array}$ & $\begin{array}{c}\mathrm{F} \\
\text { sub }\end{array}$ \\
\hline $\mathrm{SiO}_{2}$ & 83,8 & 95,8 & 87,1 & 77,5 & 83,2 & 89,0 \\
\hline $\mathrm{Al}_{2} \mathrm{O}_{3}$ & 11,3 & 3,7 & 7,7 & 11,8 & 11,4 & 7,7 \\
\hline $\mathrm{Fe}_{2} \mathrm{O}_{3}$ & 3,1 & 0,43 & 2,6 & 8,5 & 3,7 & 1,8 \\
\hline $\mathrm{ZrO}_{2}$ & 1,0 & - & 2,0 & 0,9 & 0,6 & 0,9 \\
\hline $\mathrm{TiO}_{2}$ & 0,47 & 0,045 & 0,33 & 0,95 & 0,61 & 0,29 \\
\hline $\mathrm{CaO}$ & 0,18 & - & 0,22 & 0,20 & 0,19 & 0,18 \\
\hline $\mathrm{As} \mathrm{O}_{3}$ & 0,063 & - & 0,063 & 0,072 & 0,077 & 0,062 \\
\hline $\mathrm{CuO}$ & 0,021 & 0,022 & 0,025 & 0,022 & 0,022 & 0,021 \\
\hline $\mathrm{MnO}$ & - & - & - & - & 0,028 & - \\
\hline
\end{tabular}

OBS.: Amostras A e B - Faz. Umaitá. Amostras C e D-Macaco Branco. Amostras E e F-Umbu. 
Comparando os resultados entre as amostras de mesmo ponto, percebe-se que as amostras A e B são as que mais se destacam nos valores entre o material de cobertura e o subjacente. Isso decorre devido à própria condição genética dos materiais, pois os componentes presentes na amostra A constituem as coberturas latossólicas presentes na região e/ou remanejamento destas e a B é uma amostra do facie sedimentar fluvial do Grupo Rosário do Sul, muito rico em sílica e com baixa expressividade dos demais componentes. Cabe ser destacado que esta situação é bastante clara in loco, reforçando a idéia de remanejamento do material superficial pela paleodrenagem do rio Ibicuí.

Por outro lado, analisando os dados entre os pontos percebe-se que os mesmos expressam valores que indicam aproximação ou distanciamento entre os materiais presentes em cada um.

Assim, tomando as amostras de materiais sobrejacentes (amostras A, C e E) das coberturas concrecionárias das três situações analisadas, as situações A e E expressaram valores muito próximos, pois trata-se de um mesmo material, ou pelo menos um material de cobertura sob condições idênticas de transformação (características de drenagem e condições morfológicas nas quais se encontra).

A amostra $\mathrm{C}$ apresentou um certo destaque em termos de $\mathrm{SiO}_{2}$ e diminuição nos índices de $\mathrm{Al}_{2} \mathrm{O}_{3}$ e $\mathrm{Fe}_{2} \mathrm{O}_{3}$, indicando claramente sua condição de maior alteração devido às circunstâncias já mencionadas em outras partes do trabalho.

Em relação às amostras dos materiais subjacentes (amostras B, D e F), todas apresentaram valores bem diferenciados, refletindo a própria condição dos materiais tomados para análise. Exceto a amostra B (material sedimentar fluvial do Grupo Rosário do Sul), as demais (amostras D e F) correspondem à base dos níveis concrecionários em questão. Isso explica a razão dos valores da amostra $\mathrm{F}$ (subjacente) serem tão próximos aos valores da amostra $\mathrm{C}$ (sobrejacentes). O material da amostra $\mathrm{C}$, devido a sua condição topográfica de relevo e de permeabilidade (nível concrecionário retendo água) apresenta condições de baixa drenagem, fato semelhante ao que acontece nas bases dos níveis concrecionários, pontos sujeitos a uma maior ação da água de subsuperfície.

A técnica de Difração de Raios X foi utilizada para a análise da estrutura cristalina das concreções, tendo como objetivo determinar o tamanho dos cristalitos de cada fase nas diferentes condições morfológicas das mesmas, bem como para a realização de uma análise qualitativa das quantidades de Hematita e Goethita presente nas amostras, algo que não poderia ser realizado por EDX.

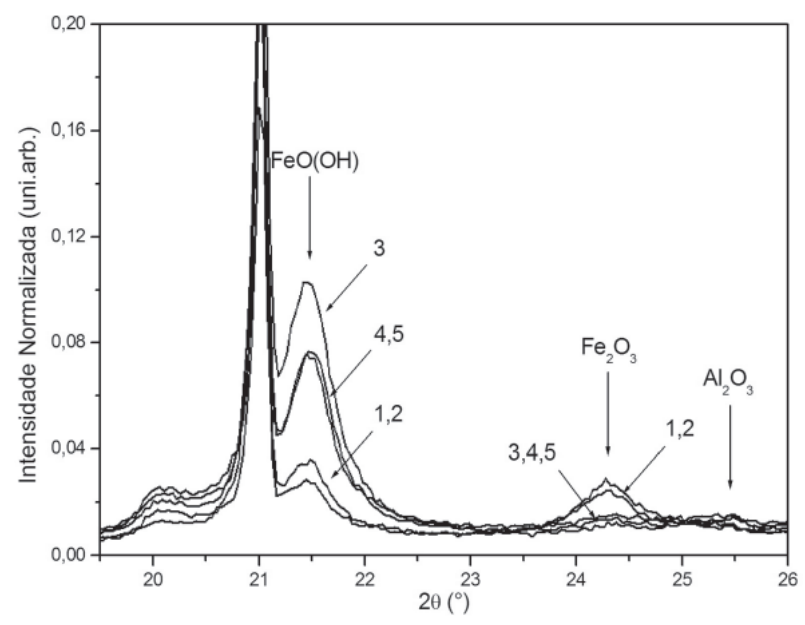

Figura 3 - Difratograma de raios X parcial das amostras de 1 e 2 (Faz. Umaitá), 3 (Macaco Branco), 4 e 5 (Umbu).

A intenção inicial era determinar quais das amostras apresentavam menor tamanho e quais apresentavam maior tamanho de cristalito, de maneira a relacionar os menores e maiores tamanhos dos cristalitos com as fases mais degradadas ou menos degradadas, respectivamente. Todavia, os dados de difração de raios $\mathrm{X}$ não mostraram variação no tamanho dos cristalitos em nenhuma das amostras analisadas, indicando que um cristalito (seja de Hematita ou Goethita) aparentemente não sofre variações significativas em sua forma e/ou estrutura depois de formado.

Por outro lado, determinou-se que os tamanhos dos cristalitos de Hematita e Goethita são diferentes, e possuem formas aproximadas diferentes. Enquanto os cristalitos de Goethita apresentam forma arredondada, com diâmetros de aproximadamente $16 \mathrm{~nm}$ em todas as direções analisadas, os cristalitos de Hematita apresentam uma forma aparentemente "chata" e planar, mais similar a uma placa ou disco, nos quais o diâmetro da placa seria de aproximadamente $24 \mathrm{~nm}$ (perpendicularmente ao eixo c cristalográfico do cristalito) e a espessura de $10 \mathrm{~nm}$ (paralelamente ao eixo c cristalográfico do cristalito). Essas informações estariam de acordo com as estruturas cristalinas de cada fase, visto que a Goethita é ortorrômbica, não apresentando um crescimento preferencial destacado do cristalito em uma ou outra direção, enquanto que a Hematita é hexagonal, apresentando crescimento preferencial distinto nas direções [001] e [110], ou seja, paralelamente e perpendicularmente ao eixo c cristalográfico dos cristalitos.

A figura 3 mostra uma região do difratograma de raios $\mathrm{X}$ para as amostras 1 a 5 . Nelas podemos ver um pico característico da Goethita $(\mathrm{FeO} . \mathrm{OH})$ e outro da Hematita $\left(\mathrm{Fe}_{2} \mathrm{O}_{3}\right)$. Como a largura dos picos de cada fase cristalina do material não variou de uma amostra a outra, e os difratogramas aqui mostrados foram normalizados pela intensidade do pico (101) 
do Quartzo, as quantidades relativas de Goethita e Hematita (área dos picos de difração referentes a cada uma das fases) podem ser retiradas dos difratogramas, mostrados nas figuras 3 e 4, por meio da comparação direta entre as alturas de cada pico.

Os dados indicam que as amostras 1 e 2 (Faz. Umaitá) possuem tanto Goethita $(\mathrm{FeO} . \mathrm{OH})$ quanto Hematita $\left(\mathrm{Fe}_{2} \mathrm{O}_{3}\right)$ em sua composição, enquanto que as amostras 3 (Macaco Branco), 4 e 5 (Umbu) possuem quase que somente Goethita em sua composição química.

Vale destacar que as linhas da Goethita em $21,5^{\circ}$ e $33,5^{\circ}$ são justamente as mais intensas de seu perfil de difração, assim como as linhas em $33,2^{\circ}$ e $35,8^{\circ}$ para a Hematita. A baixa intensidade dessas linhas, se comparadas com as do $\mathrm{SiO}_{2}$ (Quartzo) presente nas amostras, fenômeno ainda mais evidenciado pelo pequeno tamanho de cristalito encontrado (relacionado aos destacados valores para as larguras dos picos), demonstra o alto grau de desordem estrutural das fases do ferro no material, visto que a porcentagem em massa de $\mathrm{SiO}_{2}$ (como evidenciado por EDX) não é maior que duas vezes a quantidade em massa de compostos do ferro.

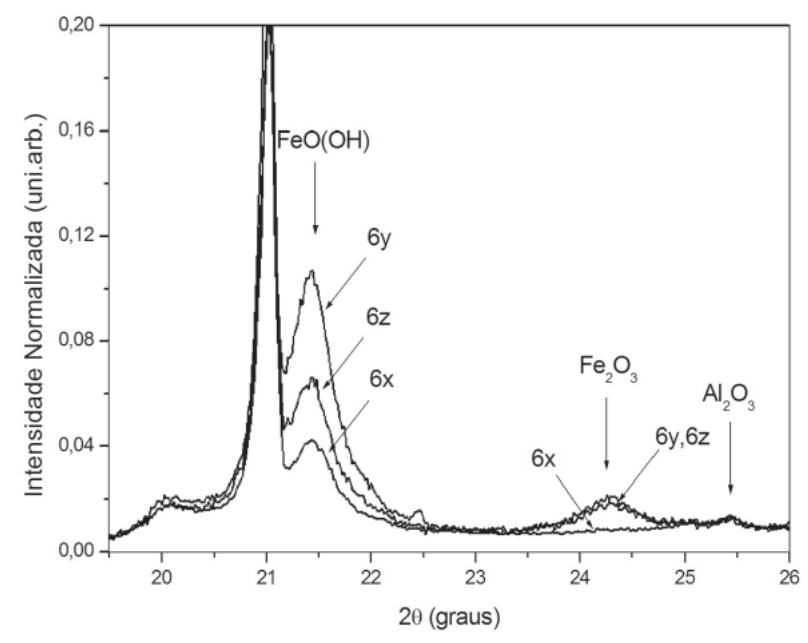

Figura 4 - Difratograma de raios X parcial das diferentes camadas da amostra 6 (externa-6x, carapaça-6y e interna-6z).

A figura 4 apresenta os difratogramas do material pulverizado de cada uma das diferentes camadas (externa-6x, carapaça-6y e interna-6z) da amostra 6. Destes perfis de difração podemos ver que a camada externa cimentante é formada somente por Quartzo e Goethita, enquanto que as camadas y (carapaça intermediária) e z (interna) apresentam, além do Quartzo, tanto Goethita quanto Hematita em sua composição. Além disso, na camada intermediária há, proporcionalmente, mais Goethita que na camada interior.
Note ainda que, tanto na figura 3 quanto na figura 4, o pico referente à fase hematita apresenta áreas praticamente iguais, indicando que a razão entre Hematita e Quartzo nas concreções estudadas é praticamente constante. Esse fato sugere que as duas fases estão intimamente relacionadas durante o processo de gênese.

Por outro lado, esses dados (figura 4) mostram que a quantidade de ferro existente no material cimentante (6x) é proporcionalmente menor que em outras amostras e/ou camadas do material, pois o pico de Goethita é tão pequeno quanto nas amostras 1 e 2, todavia, ao contrário do que ocorre com essas amostras, a camada 6x não possui picos de Hematita detectáveis. Assim sendo, os dados de XRD estão plenamente de acordo com os dados obtidos por EDX (Tabela III).

\section{Considerações finais}

A análise da morfologia e das características químicas das três variações morfológicas de formações concrecionárias em meio sedimentar revelou que há pequenas variações na composição química nestes materiais. As informações recolhidas permitem, num primeiro momento, sugerir que: 1) os níveis concrecionários pisolíticos sem depósitos de cascalheira e os níveis concrecionários em blocos constituem remanescentes de formas concrecionárias, relíquias de uma paisagem diferente da atualidade no estado e 2) os níveis concrecionários pisolíticos associados aos depósitos fluviais formam o conjunto de materiais remanejados das formas citadas anteriormente.

Neste contexto, é possível estabelecer as seguintes interpretações e explicações para a diversidade de material sedimentar de recobrimento das colinas na região:

a) as colinas - coxilhas - com presença de níveis concrecionários pisolíticos foram geradas in situ e pertencem ao conjunto de formas topográficas mais estáveis, pois constituem produtos de processos pedogenéticos que exigem uma certa estabilidade, tanto em termos ambientais, quanto tectônicos;

b) A transformação destas está principalmente vinculada a processos relacionados às mudanças de ordem ambiental e, portanto, constituem remanescentes de superfícies tectonicamente "estáveis" em meio às demais. Ou seja, fazem parte atualmente de locais sem intervenção tectônica - as colinas amplas - onde possivelmente são encontrados vestígios de paleolatossolos, os quais constituíram o material de origem dos Argissolos da região;

c) As colinas - coxilhas - com presença de concreções em blocos in situ situavam-se em superfícies tectonicamente estáveis e no presente constituem superfícies não estáveis, ou seja, cabeceiras de drenagem com processos de voçorocamentos relacionados a movimentos neotectônicos na região; 
d) As colinas - coxilhas - com presença de concreções pisolíticas associadas a depósitos fluviais, constituem as superfícies remodeladas pela dinâmica fluvial pretérita e atual. Formam, ou pelo menos formaram as superfícies instáveis derivadas dos "materiais anteriores" relacionados à dinâmica evolutiva da drenagem regional, sob a custódia da drenagem do rio Ibicuí. São os "relicários" desta bacia na Depressão Periférica.

Partindo da própria intenção do trabalho de "caracterizar o material concrecionário presente em três situações diferentes de ocorrência da mesma na região", as análises químicas por EDX permitiram verificar que o material concrecionário na forma pisolítica, independente da situação de ocorrência na localidade, são ferruginosos e homogêneos. Porém algumas diferenças podem ser estabelecidas entre ambas as formas, pois os índices dos principais componentes de interesse analisados apresentaram algumas variações.

Complementarmente à técnica de EDX, que permitiu a quantificação química das amostras, a técnica de XRD possibilitou identificar as fases do ferro presentes no material (Hematita - Fe2O3 e Goethita - FeO.OH), bem como a realização de uma análise qualitativa das mesmas. Também verificou-se que os tamanhos de cristalito de Hematita e Goethita permanecem inalterados, independentemente da situação geomorfológica na qual a amostra foi encontrada. Uma análise da largura dos picos de difração permitiu determinar os tamanhos de cristalito e suas formas aproximadas: arredondada com diâmetro de $16 \mathrm{~nm}$ para a Goethita e discóide de diâmetro $24 \mathrm{~nm}$ e espessura $10 \mathrm{~nm}$ para a Hematita.

A combinação de ambas as técnicas foi de grande valia para uma caracterização mais completa dos referidos materiais, tendo fornecido subsídios importantes para o desenvolvimento deste trabalho.

\section{Referências bibliográficas}

AB' SABER, A.N. (1964) O relevo brasileiro e seus problemas. Vol 1: 135-217. Companhia Editora Nacional. São Paulo-SP.

(1995) A revanche dos ventos: Desrruição de solos areníticos e formação de areais na Campanha Gaúcha. Ciência \& Ambiente, UFSM / Santa Maria - RS, 11: 7-31.

ALEXANDER, L.T. \& CADY, T.G. (1962) Genesis and harding of laterite in soils. Washington: USDA/ Soil Conservation Service, 90p.

BARROS SARTORI, M da G. (1993) As variações pluviométricas e o regime das chuvas na Região Central do Rio Grande do Sul. Boletim de Geografia Teorética 23 (45-46): 70-84.
BIGARELLA, J.J; BECKER, D.R. \& PASSOS, E. (1996) Estrutura e origem das paisagens tropicais e subtropicais. Vol. 2. Florianópolis. Editora da UFSC.

BOLZON, R.T. \& MARCHIORI, J.N.C. (2002) A vegetação no Sul da América: Perspectiva Paleoflorística. Ciência \& Ambiente, UFSM / Santa Maria - RS, 24: 5-24.

BRASIL (1986) Levantamentos de Recursos Naturais. RADAMBRASIL. Vol. 33.

BUHRKE, V.E.; JENKINS, R. \& SMITH, D.K. (1998) A practical guide for the preparation of specimens for $x$-ray fluorescence and $x$-ray diffraction analysis. Wiley-VCH, Nova Iorque.

CABRAL, I.L.L. (2004) Depressões interfluviais articuladas à rede de drenagem: o exemplo das bacias dos rios Ibicuizinho, Areal do Paredão, Cacequi, Santa Maria e Ibicuí. Dep. de Geografia, FFLCH / USP. Tese de Doutorado.

CABRAL, I.L.L. \& ROSS, J.L.S. (2004) O Pseudocarste em forma de depressões interfluviais e voçorocamentos em cabeceiras de drenagem como feições do desenvolvimento do relevo da Depressão Periférica - RS. Ciência e Natura / Edição Especial, UFSM / Santa Maria - RS, Agosto/2004: 445-462.

CURI, N.; LARACH, J.O.I.; KÄMPF, N.; MONIZ, A.C \& FONTES, L.E.F. (1993) Vocabulário de ciência do solo. Campinas, Sociedade Brasileira de Ciência do Solo.

DU PREEZ, J.W. (1949) Laterite: a general discussion with a description of Nigerian occurrences. Bull. Agric. Congo Belge, 40 (1): 53-60.

GUINIER, A. (1994) X-Ray Diffraction in Crystals, Imperfect Crystals, and Amorphous Bodies. Dover Publications.

HAMMOND, C. (2001) The Basics of Crystallography and Diffraction. 2a Edição. Oxford Science Publications (for the International Union of Crystallography).

JENKINS, R. (1999) X-Ray Fluorescence Spectrometry. $2^{\mathrm{a}}$ Edição. John Wiley and Sons.

LEINZ, V. (1949) Contribuição à geologia dos derrames basálticos do Sul do Brasil. Boletim da Faculdade de Filosofia, Ciências e Letras da USP, São Paulo, 103(3): 1-61. 
LEITE, P.F. (2002) Contribuição ao conhecimento fitoecológico do Sul do Brasil. Ciência e \& Ambiente, UFSM / Santa Maria - RS, 24: 51-73.

MELFI, A.J. (1997) Lateritas e processos de lateritização. Aula Inaugural de 1994, Departamento de Geotecnia, USP-São Carlos, 29p.

MEYER, R. (1987) Paléoaltérites et Paléosols: L'Empreinte du continent dans lês séries sédimentaires. Orléans. Bureau de recherches géologiques et minières. Manuels et méthodes 13.

NIMER, E. (1989) Climatologia do Brasil. Rio de Janeiro: IBGE, $2^{\circ}$ edição.

PENTEADO, M.M. (1978) Fundamentos de Geomorfologia. Rio de Janeiro: IBGE.

PERSONS, B.S. (1970) Laterite: Genesis, Location, Use. Nova Iorque, EUA, Plenum Press.

PORTO, C.G. (1996) Intemperismo em Regiões Tropicais In: GUERRA, A. J. T. \& CUNHA, S. B. da (Org.), Geomorfologia e Meio-Ambiente. Rio de Janeiro: Bertrand Brasil.
QUADROS, L.F. de \& PILLAR, V. de P. (2002) Transições Floresta-Campo no Rio Grande do Sul. Ciência e \& Ambiente, UFSM / Santa Maria - RS, 24: 109118.

SHERER, C.M. dos S.; FACCINI, U.F. \& LAVINA, E.L. (2002) Arcabouço estratigráfico do Mesozóico da Bacia do Paraná. In: HOLZ M. \& ROS L. F. de, Geologia do Rio Grande do Sul. Porto Alegre: CIGO/UFRGS. Edição revisada.

TARDY, Y. (1993) Pétrologie des Latérites et des Sols Tropicaux. Masson. Paris.

THOMAS, M.F. (1974) Tropical geomorphology. The Macmillan Press.

U.S. SOIL SURVEY STAFF (1960) Soil classification, a comprehensive system, 7 th. approximation. U.S. Agric. Dept., Washington, D. C.

VIEIRA, E.F. (1984) Rio Grande do Sul: Geografia física e vegetação. Porto Alegre: Sagra.

WARREN, B.E. (1990) X-Ray Diffraction. Dover Publications. 